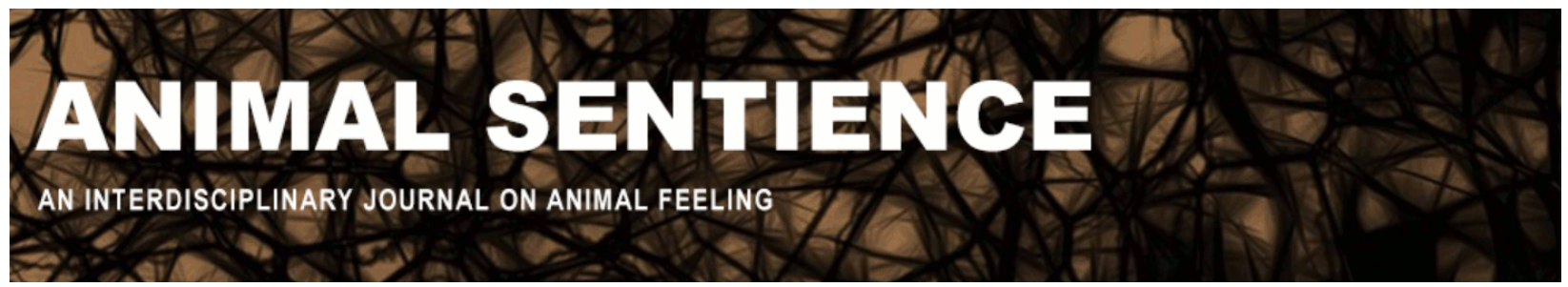

$\mathrm{Ng}$, Yew-Kwang (2019) Human superiority is obvious but does not justify cruelty. Animal Sentience 23(36)

DOI: $10.51291 / 2377-7478.1417$

Date of submission: 2019-02-12

Date of acceptance: 2019-02-20

(c)

This article has appeared in the journal Animal

Sentience, a peer-reviewed journal on animal

cognition and feeling. It has been made open access,

free for all, by WellBeing International and deposited

in the WBI Studies Repository. For more information,

please contact

wbisr-info@wellbeingintl.org.

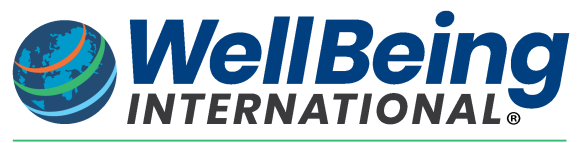

SOLUTIONS FOR PEOPLE, ANIMALS AND ENVIRONMENT 


\title{
Human superiority is obvious but does not justify cruelty
}

Commentary on Chapman \& Huffman on Human Difference

\author{
Yew-Kwang Ng \\ Economics \\ Nanyang Technological University
}

\begin{abstract}
Humans are obviously superior, in general, to other animals. This is also supported by evolution and Jerison's encephalization quotient. However, superiority does not justify cruelty towards other animals. Rather, it suggests higher responsibility. Just as adults are more capable than 2-year-olds, they also have a much higher responsibility in helping others in need, including other animals.
\end{abstract}

\begin{abstract}
Yew-Kwang $\mathrm{Ng}$, Professor of Economics, Nanyang Technological University, will join Fudan University, Shanghai, in mid-2019. Fellow, Australian Academy of Social Sciences and Distinguished Fellow, Economic Society of Australia, his recent books include: Common Mistakes in Economics by the Public, Students, Economists and Nobel Laureates (open access), and Markets and Morals (Cambridge University Press 2019). Website
\end{abstract}

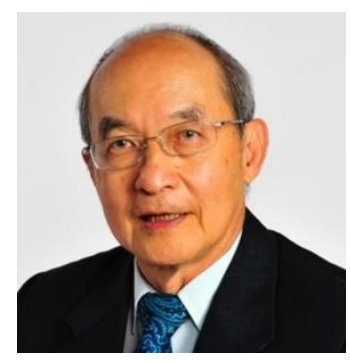

I agree with Chapman \& Huffman (2018) that the sense of human superiority has been used to support (without acceptable moral justification) human cruelty towards animals. However, I do not agree that this sense itself is "false". Rather, I strongly believe that our superiority is obvious but does not justify such cruelty, especially if it is unnecessary and could be reduced at low or even negative costs to humans ( $\mathrm{Ng} 2016 \mathrm{a}$ ).

I also agree with Juergens (2018/2019) that, "If we pride ourselves on our unique intellect, we ought to also pride ourselves on assuming the responsibility that comes with it".

1. Humans are obviously superior. Chapman \& Huffman and others are right that humans are not superior and even very inferior to some animals in some specific respects. However, taking all relevant respects together, it is obvious that humans are generally superior to all other animals. To see this point, consider the following analogies.

We know that, on average, a (human) child is superior to an adult in some respects; e.g., they have a much higher probability of surviving a fall from a 5-storey building, the ability to learn languages fast, and perhaps they have a higher degree of curiosity. However, most if not all reasonable persons also agree that, on average, an adult aged about 20-40 is generally more capable than a child of only 2 years, both physically and intellectually.

Similarly, each species is unique and may be superior to many other species in some specific respects. However, reasonable persons do not have much difficulty in seeing that, on 
average and generally (i.e., over all relevant aspects), a human person is superior to a duck which is in turn superior to an abalone. That this must be is partly, if not wholly, ensured by evolution. Only very simple living things emerged on Earth (or the universe) first, perhaps around 4 billion years ago. Having the ability to reproduce themselves (the definition of living things), they evolved through the Darwinian process of inheritance with variations (including mutation) and natural selection. Although this process of evolution does not ensure a linear increase in complexity and capability without reversals, there has been a general increase through the various stages including the single-celled organism, multi-celled organisms, invertebrates, vertebrate mammals, primates, and humans.

For example, consider the encephalization quotient of Jerison (1973, pp. 57-62). This is measured by the divergence from the equation: Brain weight $=$ Body weight to the power of $2 / 3$. The value of this power is based on the following reasoning. When a body increases proportionately in height/length, width and thickness, body weight increases by the power of 3 , and the surface area of the body increases by the power of 2 . Thus, the increase in brain size to the $2 / 3$ power is needed to coordinate the body senses and direction for body movement, due to the larger body surface area. Larger brain size beyond this equation then measures the "excess" brain size that could be devoted to higher intelligence. As shown by Jerison, this quotient increases from fish, reptiles, birds, mammals, and primates, to Homo sapiens at the very top, without much overlap.

That Homo sapiens emerged only about several hundred thousand years ago as the pinnacle of primates makes it no surprise that we have virtually dominated the Earth, including having done the most damage to its living environment. Superior capability can be used for doing both good and bad things.

2. Our superiority does not justify unnecessary cruelty. It is also obvious, as Hall (2018) and other commentators point out, that superiority does not justify cruelty. Rather, our superiority should increase our responsibility to do good. Obviously, an adult in good shape has a much higher responsibility in helping other fellow humans or other animals in need than a 2-year-old child. Thus, if we are superior to other animals in our capability, we should have a higher responsibility in preventing unnecessary suffering.

We should treat sentient nonhuman animals as worthy of moral consideration, not because their capabilities equal ours, nor because "we share an evolutionary history with them, but because they can suffer" (Shackelford 2018; Ristau 2018). However, two points have to be made here.

First, there is not just suffering, but also enjoyment. Obviously, suffering in itself is intrinsically bad. Similarly, enjoyment itself is intrinsically good. We should not look at one side only. In Woodruff's (2019) words, "It is sentience [both suffering and enjoyment], not cognitive complexity, that is the basis for the assignment of rights and the protections under the law that accompany them".

Second and relatedly, I disagree with Shackelford (2018) that "We should minimize the suffering we inflict on sentient beings - whether human or nonhuman". The surest way to minimize suffering is to destroy the whole sentient world, or even the whole living world. Suffering will be reduced to zero. Instead, we should maximize net welfare. As suffering counts as negative welfare, reducing suffering without reducing enjoyment by more will increase net 
welfare. One way to do this is by eliminating unnecessary cruelty to animals at low or even negative cost to us, as I argue in $\mathrm{Ng}$ (2016a).

Despite the concern about negative net welfare in the animal kingdom, such as by Fischer (2018) and me (Ng 1995), I am not in favour of global destruction, but rather hope for eventual salvation after significant advances in human economy, science, and morality (Ng 2016b). Our responsibility is huge indeed!

\section{References}

Chapman, C. A. and Huffman, M. A. (2018) Why do we want to think humans are different? Animal Sentience 23(1)

Fischer, B. (2018) Individuals in the wild. Animal Sentience 23(8)

Hall, T. F. (2018) Why humans are different. Animal Sentience 23(7)

Jerison, H. J. (1973). Evolution of the Brain and Intelligence. New York: Academic Press.

Juergens, U. M. (2018) Human and nonhuman animals: Equals in uniqueness. Animal Sentience 23(2)

$\mathrm{Ng}$, Y.-K. (1995) Towards welfare biology: Evolutionary economics of animal consciousness and suffering. Biology and Philosophy 10, 255-285.

$\mathrm{Ng}$, Y-K. (2016a) How welfare biology and commonsense may help to reduce animal suffering. Animal Sentience 7(1)

Ng, Y-K. (2016b) Utilitarianism generalized to include animals. Animal Sentience 7(19)

Ristau, C. A. (2018) Insulting words: "They are animals!". Animal Sentience 23(10)

Shackelford, T. K. (2018) Can they suffer? Animal Sentience 23(4)

Woodruff, M. L. (2019) Sentience is the foundation of animal rights. Animal Sentience 23(18) 